T. J. Hughes: Did you have rigid or free sliding conditions at the compression heads of the ice specimens you deformed in uniaxial compression? This is important for compressing ice with $c$-axes of crystals mostly at $45^{\circ}$ to the compression axis. Shear stresses will be created across the heads for rigid conditions. For free conditions, non-homogeneous slip in the possible slip zone may increase the shear stress resolved along the $45^{\circ}$ planes of easy glide.

SноJг: We had the rigid condition on one compression head and the free condition on the other, so there were no shear stresses across the heads. Some specimens did have nonhomogeneous slip along the $45^{\circ}$ planes, but we used data only for specimens having homogeneous slip.

J. W. GLen: Did you observe any anisotropy of transverse strain? With a $45^{\circ}$ orientation of a strong $c$-axis fabric one might expect transverse strain to be zero in the direction where basal planes intersect the normal to the compression axis.

Sнојг: I did not observe this precisely, but some specimens showed such an anisotropy after large total deformation (e.g. $30 \%$ strain).

\title{
REFERENCE
}

Weertman, J. 1973. Creep of ice. (In Whalley, E., and others, ed. Ph,ucts and chemistry of ice: papers presented at the Symposium on the Physics and Chemistry of Ice, held in Ottawa, Canada, 14-18 August 1972. Edited by E. Whalley, S. F. Jones, L. W. Gold. Ottawa, Royal Society of Canada, p. 320-27.)

\section{FINITE-ELEMENT SIMULATION OF THE BARNES IGE CAP}

\author{
By J. J. Emery, E. A. Hanafy,
}

(Department of Civil Engineering and Engineering Mechanics, McMaster University, Hamilton, Ontario L8S ${ }_{4} \mathrm{~L} 7$, Canada)

G. H. Holdsworth,

(Glaciology Division, Inland Waters Directorate, Fisheries and Environment Canada, Ottawa, Ontario $\mathrm{K}_{\mathrm{IA}} \mathrm{EE}_{7}$, Canada)

and F. Mirza

(Department of Civil Engineering and Engineering Mechanics, McMaster University, Hamilton, Ontario L8S 4 L7, Canada)

Aвstract. The finite-element method is being used to simulate glacier flow problems, with particular emphasis on the surge behaviour of the Barnes Ice Cap, Baffin Island. Following an advanced feasibility study to determine the influence of major factors such as bed topography and flow relationships, a refined simulation model is being developed to incorporate realistically: the thermal regime of the ice mass; large deformations during flow and sliding; basal sliding zones; a temperature and stress dependent ice flow relationship; mass balance; and three-dimensional influences. The findings of the advanced feasibility study on isothermal, steady-state flow of the Barnes Ice Cap are presented in the paper before turning to a detailed discussion of the refined simulation model and its application to surging. It is clear that the finite-element method allows necessary refinements not available to analytical approaches. 
The results of the advanced feasibility study are most promising from a qualitative viewpoint (i.e. the observed shift of the dynamic divide from the topographic divide, and measured trends in "steady-state" surface horizontal and vertical flow rates, were predicted), and reasonable in a quantitative sense for the horizontal steady-state surface flow rates when appropriate flow laws were adopted. A section of the paper is devoted to a discussion of appropriate functional stress-strain-rate-temperature relationships for ice. However, a number of limitations-isothermal behaviour, simplified basal sliding mechanism (linear elements), approximate bed profile, assumed flow relationships, two-dimensional model, and small deformation theory-were involved at this stage.

As a first refinement of the simulation model, emphasis was placed on the influence of the bed profile. For the Barnes Ice Cap, bed profile influences are more significant than anticipated. While the computed divide shift of $200 \mathrm{~m}$ is perhaps fortuitously close to the measured shift of $150 \mathrm{~m}$, given the approximations, it is clear that the finite-element simulation programme can be developed to give any necessary refinements. For instance, the thermal regime of the ice mass is being considered through a finite-element method transient heat-flow analysis using the heat flux (and frictional heat generation where appropriate) from the underlying rock, and glacier surface elevation-temperature data, as the basic inputs. Since step-by-step procedures have been adopted throughout, large deformations and the mass balance are also readily incorporated into the incremental, uncoupled, stress analysis. While a simple, idealized ice-cap problem is used to reduce computational time during the developmental stages, details on the application of the refined simulation to the Barnes Ice Cap and surging are given. The finite-element simulation techniques described should have other applications in ice dynamics.

\section{DISGUSSION}

D. A. Yuen: What is the Poisson ratio used in your calculations? What is the criterion for your time step?

J. J. Emery: The Poisson ratio used for the solutions reported was 0.40. This value was selected from the literature as being representative for ice at low rates of loading. Any time interval $\Delta t$ selected for a creep interval must be small enough to ensure stability of the incremental initial-strain solution process. Stability was ensured by adopting limits developed by Greenbaum (unpublished):

$$
\begin{aligned}
& \frac{\Delta \epsilon_{\mathrm{eq}}{ }^{\mathrm{c}}}{\epsilon_{\mathrm{eq}}} \leqslant \frac{\mathrm{I}}{25}, \\
& \Delta t_{n+\mathrm{I}} \leqslant \mathrm{I} .2 \Delta t_{n},
\end{aligned}
$$

where $\Delta \epsilon_{\mathrm{eq}}{ }^{\mathrm{c}}$ is the equivalent creep strain increment, $\epsilon_{\mathrm{eq}}{ }^{\mathrm{E}}$ is the equivalent elastic strain, $\Delta t$ is the time interval, and $n$ is the time step. The lowest $\Delta t$ for any element, and both limits, is used at each calculation step.

R. BRepson: When you compute $\Delta t$ at each step, do you choose a unique flow relationship for each element?

EMERY: The components of creep-strain increment $\Delta \epsilon_{i j}$ for each element and time step interval $\Delta t_{n}$ are computed from:

$$
\Delta \epsilon_{i j} \mathrm{c}=\frac{3}{2} \frac{\Delta \epsilon_{\mathrm{eq}}^{\mathrm{c}}}{\sigma_{\mathrm{eq}}} s_{i j},
$$

where $\sigma_{\text {eq }}$ is the equivalent stress, and $s_{i j}$ is the stress deviator tensor. This creep-strain increment equation is adopted from the Prandtl-Reuss incremental plastic-flow relationship. 